\title{
Pristionchus pacificus protocols *
}

\author{
Andre Pires-daSilva ${ }^{\mathcal{S}}$
}

Biology Department, University of Texas at Arlington, Arlington, TX 76019-0498, USA

\section{Table of Contents}

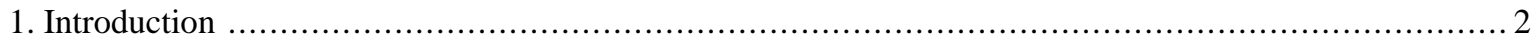

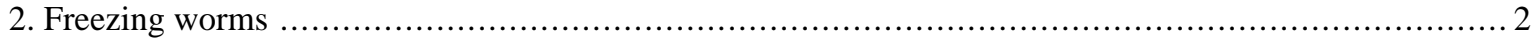

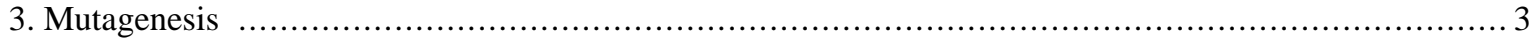

4. Construction of deletion libraries to generate $P$. pacificus gene knockouts ........................................ 4

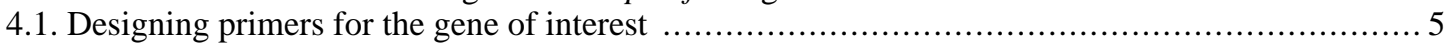

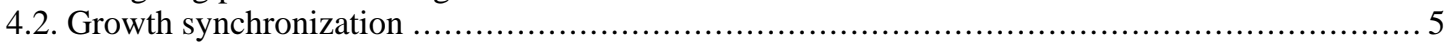

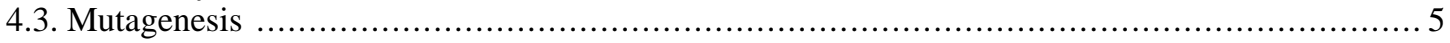

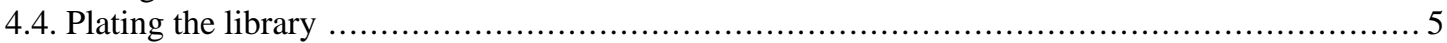

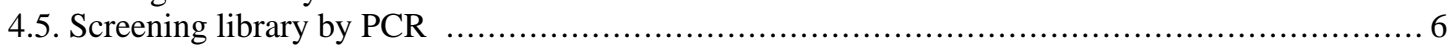

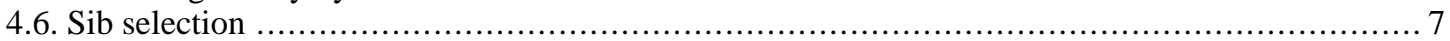

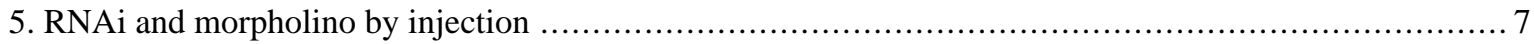

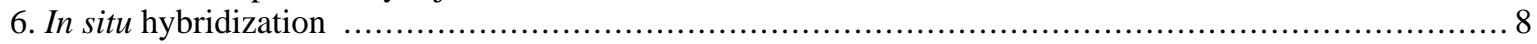

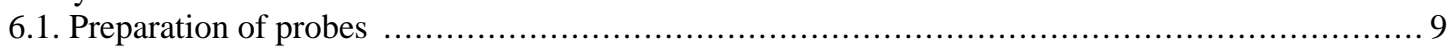

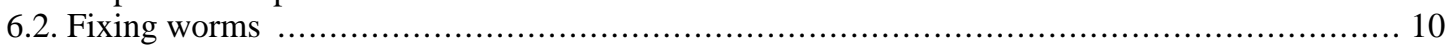

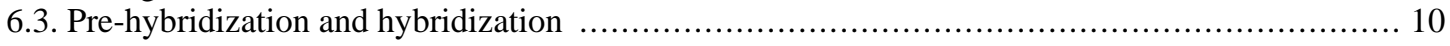

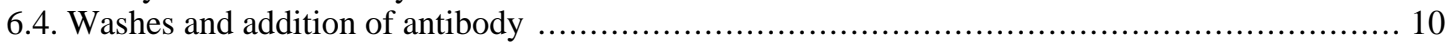

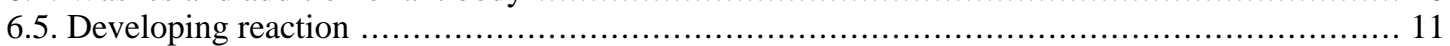

7. Isolation of $P$. pacificus genomic DNA for whole-genome sequencing …............................... 11

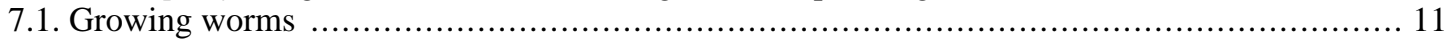

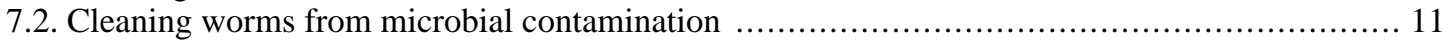

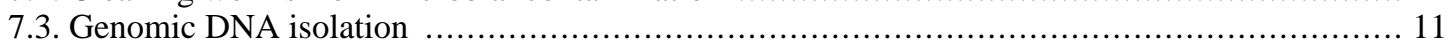

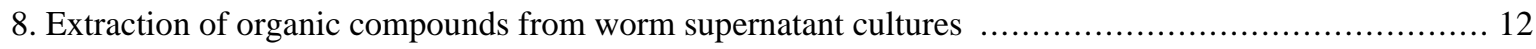

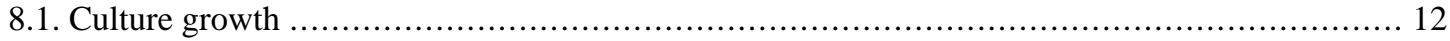

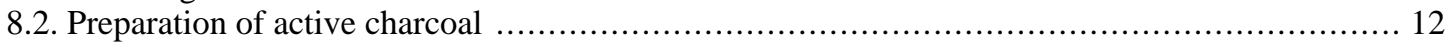

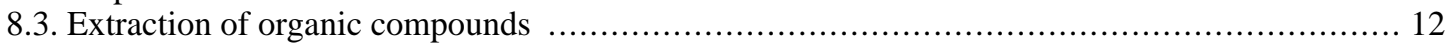

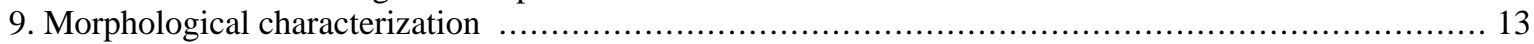

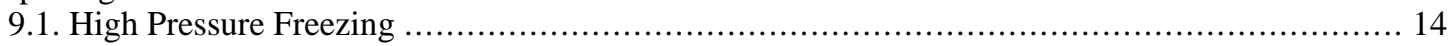

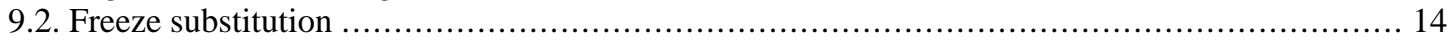

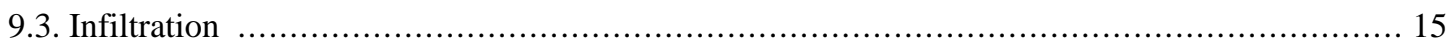

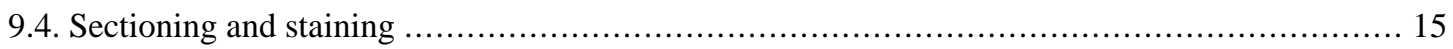

9.5. Preparation of Modified Sato's lead stain (Hanaichi et al., 1986) ................................... 15

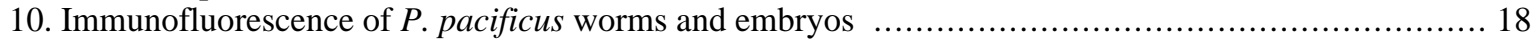

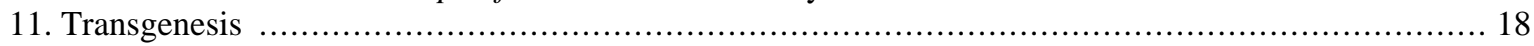

*Edited by Ralf Sommer. Last revised March 12, 2012. Published March 14, 2013. This chapter should be cited as: Pires-daSilva, A. Pristionchus pacificus protocols (March 14, 2013), WormBook, ed. The C. elegans Research Community, WormBook, doi/10.1895/wormbook.1.114.2, http://www.wormbook.org.

Copyright: (C) 2013 Pires-daSilva A. This is an open-access article distributed under the terms of the Creative Commons Attribution License, which permits unrestricted use, distribution, and reproduction in any medium, provided the original author and source are credited.

${ }^{\S}$ To whom correspondence should be addressed. E-mail: apires@uta.edu 


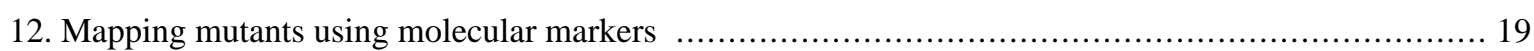

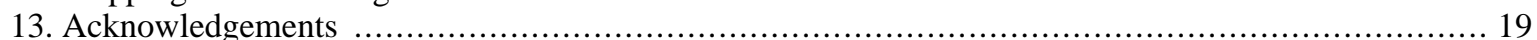

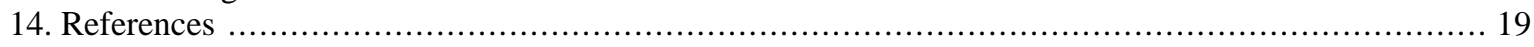

\section{Introduction}

The diplogastrid nematode Pristionchus pacificus has been recently established as a new genetic model system for evolutionary studies. Forward and reverse genetics tools have been developed to allow detailed comparisons to the rhabditid nematode $C$. elegans. $P$. pacificus has distinctive body morphology and diverges in development both at the cellular and molecular level when compared to $C$. elegans (see Pristionchus pacificus, http://doi/10.1895/wormbook.1.102.1). Despite these differences, P. pacificus shares many traits with C. elegans that are of advantage for genetic analyses: it is hermaphroditic, has a small genome size $(169 \mathrm{Mb})$, small number of chromosomes (haploid set with 5 autosomes and 1 sex chromosome), short life-cycle (4 days at $20{ }^{\circ} \mathrm{C}$ ), and produces large brood sizes (120-180 eggs). Similarly to C. elegans, P. pacificus has 4 larval stages (J1-J4). However, the first larval stage molts within the eggshell (Sudhaus and Fürst von Lieven, 2003).

\section{Freezing worms}

P. pacificus can be frozen in liquid nitrogen, although with lower efficiency than C. elegans. The following protocol was adapted from a procedure employed to freeze parasitic nematodes (Nolan et al., 1988). Cryopreservation of $P$. pacificus using this protocol has been successful even for mutants that failed to freeze with other protocols (R. Hong, personal communication).

\section{Protocol 1. Freezing P. Pacificus}

\section{Equipment and Reagents}

- Freezing solution (FS): 4 ml DMSO (Dimethyl sulfoxide), 4 g Dextran (MW 8500-11500, Sigma-Aldrich D9260, from Leuconostoc mesenteroides), complete volume up to $40 \mathrm{ml}$ with sterile distilled water. Store solution at 4 ${ }^{\circ} \mathrm{C}$.

- Thawing solution (TS): L-Glutamine (1X, $300 \mathrm{mg} / \mathrm{L}$ glutamine in M9). Store solution at $4{ }^{\circ} \mathrm{C}$.

- $\quad$ M9 Buffer (see Maintenance of C. elegans, http://doi/10.1895/wormbook.1.101.1) containing $1 \mathrm{mM} \mathrm{CaCl}_{2}$.

- $1.8 \mathrm{ml}$ cryogenic vials.

1. Add FS to old worm plates with mostly J2s and dauers ( 2 week old). Remember that the agar will soak up some of the liquid depending on the dryness of the media. Exposure of worms to DMSO should be limited to less than 1 hour.

2. Aliquot $1 \mathrm{ml}$ of the mixture into $1.8 \mathrm{ml}$ cryogenic vials labeled with the strain name and date.

3. Put cryogenic vials into a polystyrene foam tube tray and cover with another (an alternative is to take a Nalgene ${ }^{\circledR}$ Cryo $1{ }^{\circ} \mathrm{C}$ Freezing Container filled with $100 \%$ isopropyl alcohol). Fasten the racks with a rubber band, enclosing the samples inside the box. This ensures a slow constant rate of cooling.

4. Place the box at $-80^{\circ} \mathrm{C}$ for more than 3 days.

5. Move the vials to the permanent location in a liquid nitrogen tank.

6. To check for successful freezing, thaw a duplicate line at room temperature.

7. Wash away DMS with 10X the freezing volume with TS.

8. Centrifuge lightly at $150 \times \mathrm{g}$ for 1 minute to spin down worms.

9. Repeat wash with M9 buffer and centrifuge again. 
10. Remove supernatant, transfer worms at the periphery of OP50 NGM plates.

11. Wait 4 days for viable larvae to emerge.

\section{Mutagenesis}

Ethyl methanesulfonate (EMS) has been widely used in P. pacificus to isolate a wide variety of mutants with defects in the egg-laying system, muscle, sex determination, dauer formation, behavior, and gonad formation (Protocol 2). The protocol for EMS mutagenesis used is the same as for C. elegans (Brenner, 1974). For mutagenizing $P$. pacificus with psoralen, however, some modifications were introduced (Protocol 3).

\section{Protocol 2. EMS mutagenesis}

Caution: EMS is a very strong mutagen and should be handled in a fume hood. All materials (gloves, pipettes, tips) that have been in contact with this mutagen should be treated with $1 \mathrm{~N} \mathrm{NaOH}$ to inactive the EMS.

\section{Equipment and Reagents}

- M9 Buffer.

- $\quad$ EMS (ethyl methanesulfonate; Sigma-Aldrich M0880).

- Well fed, young adult P. pacificus worms.

- NGM plates seeded with E. coli OP50 (see Maintenance of C. elegans, http://doi/10.1895/wormbook.1.101.1).

1. Wash the worms from 4-5 $6 \mathrm{~cm}$ diameter plates using $2 \mathrm{ml}$ of $\mathrm{M} 9$ for each plate. Collect in a $15 \mathrm{ml}$ tube.

2. Centrifuge for $5 \mathrm{~min}$. at $1500 \times \mathrm{g}$ and resuspend the worms in $2 \mathrm{ml} \mathrm{M}$.

3. Add $20 \mu \mathrm{l}$ of EMS into another tube containing $2 \mathrm{ml}$ of M9. Swirl the tube until the EMS has dissolved.

4. Add the EMS solution to the worms (this concentration of EMS corresponds to $47 \mathrm{mM}$ ). Incubate the worms at $20^{\circ} \mathrm{C}$ for $3.5 \mathrm{hrs}$. in horizontal position, on a rocker at low speed (40UPM).

5. Incubate for $30 \mathrm{~min}$. in a vertical position to let worms sink.

6. Remove as much supernatant as possible. Discard the supernatant to a container with $1 \mathrm{~N} \mathrm{NaOH}$ to inactivate the EMS.

7. Wash the worms 3 times with $5 \mathrm{ml}$ of $\mathrm{M} 9$, and centrifuge each time at $1500 \times \mathrm{g}$ for $5 \mathrm{~min}$.

8. Resuspend the worms in $500 \mu \mathrm{l}$ of M9 and dispense them onto 2 NGM plates with OP50.

9. After the solution has soaked in the plate, pick moving J4 animals to new plates.

10. Depending on the mutation of interest (dominant, recessive, maternal effect), pick animals of the relevant generation onto fresh plates, and screen for desired mutant phenotypes.

Protocol 3. Psoralen mutagenesis (modified from Yandell et al., 1994)

\section{Equipment and Reagents}

- M9 Buffer.

- $3 \mathrm{mg} / \mathrm{ml}$ TMP solution in DMF (Trioxsalen; Sigma-Aldrich T6137; 4,5',8-Trimethylpsoralen).

- Well fed, young adult P. pacificus worms. 
- Unseeded and seeded NGM agar plates.

- Long-wave ultraviolet (UV) source (365 nm; Model UVL-21 Blak-Ray lamp, UVP, Fisher Scientific cat no. 11-984-40).

- UV intensity meter (Model J-221, UVP).

- Rocker.

1. Wash the worms from 4-5 $6 \mathrm{~cm}$ diameter plates using $2 \mathrm{ml}$ of $\mathrm{M} 9$ for each plate. Collect in a $15 \mathrm{ml}$ tube.

2. Using M9 buffer, wash worms off NGM plates, and combine in a $15 \mathrm{ml}$ tube.

3. Wash 2 times with M9, each time pelleting worms at $1500 \times \mathrm{g}$ for $5 \mathrm{~min}$.

4. Remove as much liquid as possible and resuspend in $30 \mu \mathrm{g} / \mathrm{ml}$ of TMP, e.g., $20 \mu \mathrm{lof}$ TMP $(3 \mathrm{mg} / \mathrm{ml})$ in 2 $\mathrm{ml}$ of M9.

Note: the worms should be resuspended in about 10 times their volume.

5. Wrap the tube in aluminum foil and incubate the worms for $15 \mathrm{~min}$. at RT on a rocker at low speed (40 UPM). Afterwards, incubate for 5 min. at a vertical position to let worms sink.

6. Remove worms with a Pasteur pipette and place them in an unseeded worm agar plate at $20-25^{\circ} \mathrm{C}$. Wrap the plate in aluminum foil and let excess TMP to soak into the plate.

7. Calibrate the distance between the long-wave UV source and the plate using the UV intensity meter. Irradiate the worms for 50 seconds at $500 \mu \mathrm{W} / \mathrm{cm}^{2}$ (the distance between the plate and the UV lamp is about $10 \mathrm{~cm})$.

8. Keep the worms in the dark for $5 \mathrm{hrs}$.

9. Transfer worms to seeded plates.

\section{Construction of deletion libraries to generate $P$. pacificus gene knockouts}

A powerful method to isolate $C$. elegans mutants in a gene of interest for which sequence information is available is by chemical mutagenesis followed by polymerase chain reaction (PCR). The generation of knockouts in a high throughput manner by using deletions in a library of worms has proven very successful for $C$. elegans. The protocol adopted for $P$. pacificus does not include the freezing of the library, since the efficiency of recovery following freezing of $P$. pacificus is too low. The library comprises 1296 -well microtiter plates and includes the arrayed progeny of nearly $5 \times 10^{5} \mathrm{~F} 1$ animals representing $10^{6}$ mutagenized genomes. Worms are grown in plates until the food is exhausted, generating, on the average, $100 \mathrm{~F} 2$ progeny per F1 animal.

\section{Protocol 4. Deletion library}

\section{Equipment and Reagents}

- M9 Buffer.

- Basic hypochlorite solution: $30 \mathrm{ml} 0.1 \mathrm{M} \mathrm{NaCl}, 5 \mathrm{ml} 5 \mathrm{M} \mathrm{NaOH}$ and $10 \mathrm{ml}$ 6\% Sodium hypochlorite.

- Wild type worms.

- 130 NGM plates (10 $\mathrm{cm}$ diameter) seeded with $1 \mathrm{ml}$ of OP50.

- 1200 NGM plates ( $6 \mathrm{~cm}$ diameter) seeded with $100 \mu \mathrm{l}$ of OP50. 
- 12-well NGM plates seeded with $50 \mu$ of OP50.

- $20 \mathrm{ml} \mathrm{10X}$ lysis buffer $\left[10 \mathrm{ml} 1 \mathrm{M} \mathrm{KCl}, 2 \mathrm{ml} 1 \mathrm{M}\right.$ Tris $\mathrm{pH} 8.2,0.5 \mathrm{ml} 1 \mathrm{M} \mathrm{MgCl}_{2}, 0.9 \mathrm{ml} \mathrm{NP}-40,0.9 \mathrm{ml}$ Tween-20, fill to $20 \mathrm{ml}$ with water].

- Proteinase K $10 \mathrm{mg} / \mathrm{ml}$.

- MicroAmp® Clear Adhesive Film (Applied Biosystems ${ }^{\circledR}$ ).

- Oven $65^{\circ} \mathrm{C}$.

- Refrigerated incubator at $12{ }^{\circ} \mathrm{C}$.

- $1.2 \mathrm{ml}$ 96-well plates.

- $200 \mu 1$ 96-well plates.

- 10X yellow loading dye (6 g Ficoll, $30 \mathrm{mg}$ Tartrazine, to $30 \mathrm{ml}$ with water).

\subsection{Designing primers for the gene of interest}

Target a region of around $1.5 \mathrm{kbp}(1.0-2.5 \mathrm{kbp})$, with nested oligonucleotides of around $20 \mathrm{bp}$ (annealing temperature of $60{ }^{\circ} \mathrm{C}$ ). The larger the region targeted, the more difficult it is to detect small mutations in agarose gels. The smaller the region, the more difficult it is to find a deletion that happens to have occurred between the primers.

\subsection{Growth synchronization}

1. Transfer freshly starved larvae from $106 \mathrm{~cm}$ diameter plates to $1510 \mathrm{~cm}$ diameter plates seeded with $1 \mathrm{ml}$ of OP50 per plate. Incubate at $25{ }^{\circ} \mathrm{C}$ (or $20^{\circ} \mathrm{C}$ ) until plates are full of eggs.

2. Transfer worms and eggs to a $50 \mathrm{ml}$ conical tube with $\mathrm{M} 9$ and centrifuge for $5 \mathrm{~min}$. at $1300 \times \mathrm{g}$. Discard the supernatant. Add $30 \mathrm{ml}$ of basic hypochlorite solution and incubate at room temperature (RT) for about 4 min. Collect the eggs by centrifugation $(2000 \times \mathrm{g}, 5 \mathrm{~min}$.).

3. Wash the eggs 2 times with $30 \mathrm{ml}$ of water and 1 time with $30 \mathrm{ml}$ of $\mathrm{M} 9$ buffer. Leave the worms to hatch overnight in the buffer or in a $10 \mathrm{~cm}$ unseeded NGM plate.

4. The next day, pipet $10 \mu \mathrm{l}$ of the suspension onto each of 3 plates and count to determine titer. The total number

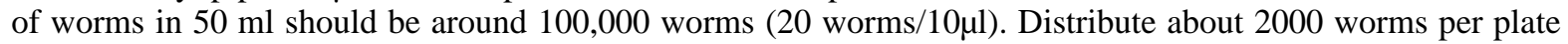
onto 50 seeded $10 \mathrm{~cm}$ NGM plates.

\subsection{Mutagenesis}

5. Culture synchronized culture of worms for about $52 \mathrm{hrs}$. at $20^{\circ} \mathrm{C}$. Follow protocol 3 for TMP/UV mutagenesis. After mutagenesis, plate the worms on 50 fresh seeded $10 \mathrm{~cm}$ NGM plates, with 2000 worms/plate.

\subsection{Plating the library}

6. After a couple of days, when P0s have laid the F1 eggs, bleach the $5010 \mathrm{~cm}$ plates (as in part B, 2) and leave the eggs in $50 \mathrm{ml}$ of M9 buffer overnight.

7. The following day, count the number of L1 worms. Distribute about $400 \mathrm{~F} 1 \mathrm{~s} / \mathrm{small}$ plate (total $12006 \mathrm{~cm}$ plates).

8. Wait one generation, until the F2 eggs have hatched. Wash plates by adding $800 \mu \mathrm{l}$ of water and transferring 150 $\mu \mathrm{l}$ of the $\mathrm{L} 1$ suspension into a $1.2 \mathrm{ml}$ 96-well plate (to avoid mistakes, leave the yellow tip inside the well). This step will take about $30 \mathrm{~min} . /$ plate; in total it will result in $12 \times 96$-well plates. Leave the washed plates at RT until they dry. Then transfer them to $12{ }^{\circ} \mathrm{C}$. 
9. Add $150 \mu \mathrm{l}$ of lysis buffer + Proteinase $\mathrm{K}(120 \mu \mathrm{g} / \mathrm{ml})$ to each well of the $1.2 \mathrm{ml}$ 96-well plates, seal them with MicroAmp Clear Adhesive Film and incubate them first at $-80{ }^{\circ} \mathrm{C}$ for $2 \mathrm{hrs}$. and then at $65{ }^{\circ} \mathrm{C}$ overnight with shaking.

10. The following morning, centrifuge the $96-$ well plates for $10 \mathrm{~min}$. at $4000 \mathrm{rpm}$.

11. Transfer $150 \mu \mathrm{l}$ of the suspension into a $200 \mu \mathrm{l} 96$-well plate and inactivate the Proteinase $\mathrm{K}$ at $95{ }^{\circ} \mathrm{C}$ for $10 \mathrm{~min}$. The remaining $150 \mu \mathrm{l}$ should be stored at $-80^{\circ} \mathrm{C}$.

12. Pool the rows and columns from each of the 12 plates by combining $75 \mu$ of each of the wells into a single 1.2 $\mathrm{ml}$ 96-well plate. For example, pool wells A1 of all 12 plates into the position A1 of the $1.2 \mathrm{ml}$ 96-well plate. Repeat this procedure for each well, making a total of 96 pools. This is the master plate with pooled DNA.

\subsection{Screening library by PCR}

13. Take $5 \mu \mathrm{l}$ as template for a $20 \mu \mathrm{l}$ PCR reaction. It is necessary to perform nested PCR. For the $2^{\circ}$ round, use $1 \mu \mathrm{l}$ of the $1^{\circ}$ round.

\section{Example for PCR mix:}

$1^{\text {st }} \underline{\text { PCR round: (final Volume } 10 \mu \mathrm{l} \text { ) }}$

$\begin{array}{ll}\mathrm{H}_{2} \mathrm{O} & 1.7 \mu \mathrm{l} \\ \mathrm{dNTP}(10 \mathrm{mM} \text { each of dATP, dCTP, dGTP, dTTP) } & 0.2 \mu \mathrm{l} \\ \text { forward primer }(10 \mu \mathrm{M}) & 0.5 \mu \mathrm{l} \\ \text { reverse primer }(10 \mu \mathrm{M}) & 0.5 \mu \mathrm{l} \\ \text { Buffer } 5 \mathrm{X} & 2.0 \mu \mathrm{l} \\ \text { Taq }(5 \mathrm{U} / \mu \mathrm{l}) & 0.1 \mu \mathrm{l} \\ \text { DNA (pooled Library) } & 5.0 \mu \mathrm{l}\end{array}$

$94^{\circ} \mathrm{C}$ for $2 \mathrm{~min}$.

$94^{\circ} \mathrm{C}$ for $30 \mathrm{sec}$.

$58^{\circ} \mathrm{C}$ for $20 \mathrm{sec} .35$ cycles

$72^{\circ} \mathrm{C}$ for $3 \mathrm{~min}$.

$72^{\circ} \mathrm{C}$ for $6 \mathrm{~min}$.

add $20 \mu \mathrm{l} \mathrm{H} 2 \mathrm{O}$ to $1^{\circ}$ round.

$2^{\underline{\text { nd }}} \stackrel{\text { PCR round: (final Volume } 10 \mu \mathrm{l} \text { ) }}{ }$

$\mathrm{H}_{2} \mathrm{O} \quad 3.7 \mu \mathrm{l}$

dNTP (10 mM each of dATP, dCTP, dGTP, dTTP) $\quad 0.2 \mu \mathrm{l}$

forward primer $(10 \mu \mathrm{M}) \quad 0.5 \mu \mathrm{l}$

reverse primer $(10 \mu \mathrm{M}) \quad 0.5 \mu \mathrm{l}$

Buffer $5 \mathrm{X} \quad 2.0 \mu \mathrm{l}$

Taq $(5 \mathrm{U} / \mu \mathrm{l}) \quad 0.1 \mu \mathrm{l}$

yellow Loading dye $\quad 2.0 \mu \mathrm{l}$

DNA (1:3 diluted) $\quad 1.0 \mu \mathrm{l}$

Same cycling conditions as $1^{\text {st }}$ round. 
14. Select samples which show bands that are smaller than the wild-type for further tests. Determine the precise address of the candidate sample by repeating the PCR using $5 \mu$ of the corresponding well of each of the twelve 96-well plates ( $200 \mu \mathrm{l} 96-$-well plates). This will give the number of the plate (2-A5, for example).

\subsection{Sib selection}

15. Resuspend the original plate in $50 \mathrm{ml}$ water or $\mathrm{M} 9$ ( $50 \mathrm{ml}$ conical tube). Count the number of worms $/ \mu \mathrm{l}$, by pippeting $3 \times 10 \mu$ into a plate. Calculate the average of worm $/ \mu l$.

16. Dispense 50 worms into each well of 812 -well plates. The remaining worms (which were not dispensed) should be centrifuged and put back in the original plate, without bacteria. Keep this plate at $12{ }^{\circ} \mathrm{C}$.

17. Culture the worms at $20{ }^{\circ} \mathrm{C}$ for 5 days. Harvest a portion of each well by washing with $300 \mu \mathrm{l}$ of water. Transfer $75 \mu \mathrm{l}$ of the suspension into a $1.2 \mathrm{ml}$ 96-well plate, plus $75 \mu \mathrm{l}$ lysis buffer with Proteinase K. Incubate overnight at $65^{\circ} \mathrm{C}$ with shaking. The agar plates with worms should be kept at $12{ }^{\circ} \mathrm{C}$.

18. Transfer $100 \mu \mathrm{l}$ to a $200 \mu \mathrm{l} 96$-well plate.

19. Inactivate the Proteinase $\mathrm{K}$ by incubating the 96 -well plate at $95^{\circ} \mathrm{C}$ for $15 \mathrm{~min}$.

20. Screen the plate by PCR ( $5 \mu$ l as template), identify the plate and repeat procedure by dispensing $96 \times 15$ worms/plate.

21. Repeat procedure above with 5 worms/plate and later 1 worm/plate.

\section{RNAi and morpholino by injection}

The possibility of rapidly knocking-down genes by RNA interference (RNAi), together with the availability of the C. elegans genome sequence, stimulated the study of gene function in a global scale (see Reverse Genetics, http://doi/10.1895/wormbook.1.47.1). Currently there are four different ways of delivering double-stranded RNA (dsRNA) into C. elegans: injection, soaking, feeding and bombardment. Preliminary experiments with P. pacificus indicate that RNAi works when injecting dsRNA into the gonad, but not by soaking or feeding. Bombardment has not been tried. When compared to C. elegans, $P$. pacificus is more difficult to inject because the syncytial part of the gonad is shorter and because the syncytium lies along the left-right axis (Cinkornpumin and Hong, 2011).

The conditions used for dsRNA preparation and injection were basically the same as described for C. elegans (see Reverse genetics, http://doi/10.1895/wormbook.1.47.1), with a few modifications. The injection of a $1081 \mathrm{bp}$ Ppa-tra-1 dsRNA into wildtype worms, for instance, resulted in $20 \%(\mathrm{n}=346)$ progeny with the transformer phenotype. Injections of a 464 bp Ppa-prl-1 dsRNA into a prl-1 gain-of-function allele on the other hand, resulted in $\sim 37 \%$ of injected P0 worms ( $\mathrm{n}=59$ ) having F1's with the non-roller phenotype (10\% penetrance) (R. Hong, personal communication). For genes involved in vulva development, however, the efficiency of the RNAi seems to be much lower (Zheng and Sommer, personal communication). Similar observations have been made with vulva genes in $C$. elegans (Chen and Greenwald, 2004). Another knockdown technology, using morpholino oligonucleotides, has proven robust for P. pacificus (Protocol 5) (Pires-daSilva and Sommer, 2004; Zheng et al., 2005). Morpholino-oligonucleotides, widely used for knocking down genes in other model systems (e.g., sea urchin, zebrafish), are modified oligonucleotides that efficiently block the translation or splicing of specific mRNAs. The properties of morpholino oligonucleotides, which combine nuclease-resistance, water-solubility and high specificity, are of major advantage. However, the injection of morpholinos causes a high rate of lethality in the P. pacificus F1 progeny (about 50\%). When selecting oligo sequences, it is recommended to design at least two non-overlapping oligos. In this way, the consistency of the resulting phenotype can be tested. A good target sequence has minimal mRNA secondary structure and includes the translational start codon and/or the 5'UTR region. 


\section{Protocol 5. Injection of morpholino oligonucleotides}

\section{Equipment and Reagents}

- Agarose.

- Glass coverslips $(22 \times 50)$.

- Tips for injection Microloader (Eppendorf).

- Light mineral oil (Sigma-Aldrich M3516).

- Glass thin filaments $1.0 \mathrm{~mm}$ (World Precision Instruments).

- Transjector (Eppendorf 5246).

- Micropippete puller.

- Inverted microscope (Zeiss Axiovert 135).

- Morpholino oligonucleotides (Gene Tools, LLC).

1. Prepare $5 \mathrm{ml}$ of $2 \%$ agarose in water, and melt it in the microwave.

2. Drop the melted agarose on to a coverslip. Put another coverslip on top. Repeat this procedure for 10 more pairs of coverslips.

3. Separate the two coverslips and leave the agarose pad in an $80{ }^{\circ} \mathrm{C}$ drying oven for $1 \mathrm{hr}$.

4. Dissolve the oligonucleotide to $100 \mu \mathrm{M}$ in water.

5. Pull a glass thin filament with the needle puller (the tip of the needle should taper quickly and smoothly).

6. Load about $500 \mu \mathrm{l}$ of the morpholino into the needle using Microloader tips. To discard bubbles accumulating in the tip of the needle, hold the loaded needle in vertical position for a few min.

7. Attach the needle to the transjector. To break the tip of the needle, rub the end of the tip against a thin glass bar immersed in light mineral oil. Monitor the flow of liquid out of the needle under the 40X objective.

8. Add a drop of the light mineral oil to the agarose pad. Pick a few worms and place them into the oil. Gently force the worms to the agarose pad with the wormpick, so that the entire body of the worm sticks to the pad.

9. After aligning the needle with the worms, move the gliding stage against the tip of the needle. In this way the needle will penetrate the cuticle of the worm and reach the gonad. Apply pressure to expel the morpholino solution into the gonad.

10. Recover the worms from the agarose pad by adding a drop of M9 buffer onto the surface of the oil. Transfer worms to a freshly seeded plate using a pick.

\section{In situ hybridization}

To characterize gene function, it is useful to characterize the temporal and spatial pattern of gene expression during development. Here we describe a protocol used for $P$. pacificus to characterize expression during larval development. Although the following protocol employs $48{ }^{\circ} \mathrm{C}$ for the temperature of pre-hybridization, hybridization and washing steps, the temperature may have to be optimized for each probe. 


\section{Protocol 6. In situ hybridization in P. pacificus}

To prevent RNase contamination, volume measurements are made with disposable plastic conical tubes. Bench surfaces are sprayed with RNase-AWAY® (Molecular BioProducts ${ }^{\circledR}$ 7003) and wiped clean with Kimwipes ${ }^{\circledR}$.

\section{Equipment and Reagents}

- PBS: Make a 10X stock solution according to standard protocol (Sambrook and Russell, 2001).

- PBTw: $1 X$ PBS containing 0.1\% Tween 20.

- Methanol at $-20^{\circ} \mathrm{C}$.

- Acetone at $-20^{\circ} \mathrm{C}$.

- $20 \mu \mathrm{g} / \mathrm{ml}$ Proteinase K in PBTw buffer.

- $2 \mathrm{mg} / \mathrm{ml}$ glycine in PBTw buffer.

- Fixative solution: 1X PBS, 0.08 M Hepes pH 6.9, 1.6 mM MgSO, $0.8 \mathrm{mM} \mathrm{EGTA,} \mathrm{3.7 \%} \mathrm{formaldehyde.}$

- Hybridization buffer: 5X SSC, 50\% deionized formamide, $100 \mu \mathrm{g} / \mathrm{ml}$ herring sperm DNA, $50 \mu \mathrm{g} / \mathrm{ml}$ Heparin and $0.1 \%$ Tween-20 (store at $-20{ }^{\circ} \mathrm{C}$ ).

- Alkaline-phosphatase-conjugated anti-DIG (Roche) diluted 1:1000.

- Staining solution: $100 \mathrm{mM} \mathrm{NaCl}, 5 \mathrm{mM} \mathrm{MgCl}, 100 \mathrm{mM}$ Tris (pH 9.5), 0.1\% Tween-20, $1 \mathrm{mM}$ Levamisole (Levamisole is a potent inhibitor of endogenous phosphatases). Tris pH 9.5 is made from the certified source (Fisher Scientific), with a $\mathrm{pH}$ probe that is treated with RNase away. Staining solution should be made fresh every time, because diluted Tris $\mathrm{pH} 9.5$ is not stable.

- SigmaFast ${ }^{\mathrm{TM}} \mathrm{BCIP} \circledast / \mathrm{NBT}$ tablet (Sigma-Aldrich B5655): dissolve one tablet in $10 \mathrm{ml}$ staining solution.

- Dig DNA labeling Mix, 10X concentration (Roche).

- QIAquick® PCR Purification kit (Qiagen \#28104).

\subsection{Preparation of probes}

Probes for in situ with DIG or FITC (UTP) labeled RNA are more specific and give less background than probes using labeled DNA. Follow DIG-UTP or FITC-UTP labeling protocol from Roche (DIG KIT \#11175025910 or FITC mix \#11685619910). The template for an antisense RNA probe is a PCR product of the gene of interest amplified with the appropriate forward facing 30-mer oligo and a reverse T7-tagged oligo (add the T7 recognition sequence to the 5' end of your 25-28 mer sequence: 5'-TAATACGACTCACTATAGGGACT-3'). The PCR product can be stored indefinitely at $-20^{\circ} \mathrm{C}$.

PCR product:

DIG UTP

10X transcription buffer

RNase inhibitor

T7 RNA polymerase

DEPC ddH 20
$3-8 \mu \mathrm{l}$

$1 \mu \mathrm{l}$

$1 \mu \mathrm{l}$

$0.5 \mu \mathrm{l}$

$1 \mu \mathrm{l}$

up to $10 \mu \mathrm{l}$ 
Incubate at $37^{\circ} \mathrm{C}$ for $2 \mathrm{hrs}$. to overnight.

Add $50 \mu \mathrm{l}$ DEPC ddH20 and another $0.5 \mu \mathrm{l}$ Rase inhibitor.

Probes can be stored in aliquots at $-20{ }^{\circ} \mathrm{C}$ for many months or longer.

\subsection{Fixing worms}

1. Wash worms out of 3 plates with M9.

2. Centrifuge worms at $2000 \mathrm{rpm}$ for $1 \mathrm{~min}$. (use this parameter for every step in which worms are centrifuged in this protocol).

3. Wash worms twice with M9.

4. Resuspend the worms in $1000 \mu \mathrm{l}$ methanol at $-20{ }^{\circ} \mathrm{C}$ and incubate them for $10 \mathrm{~min}$. in the same temperature. At this point samples can be stored for an indefinite amount of time.

5. Remove supernatant and add $1000 \mu \mathrm{l}$ acetone at $-20^{\circ} \mathrm{C}$ for $10 \mathrm{~min}$.

6. Add $1000 \mu$ lixative solution and incubate at RT for $10 \mathrm{~min}$. Place samples on a shaking platform to ensure well mixing.

7. Submit samples to 5 freeze-thaw cycles (liquid Nitrogen and $50{ }^{\circ} \mathrm{C}$ water bath).

8. Incubate samples for $20 \mathrm{~min}$. at RT.

9. Wash twice in PBTw buffer, 5 min. each.

10. Incubate in $1000 \mu \mathrm{l}$ Proteinase $\mathrm{K}(20 \mu \mathrm{g} / \mathrm{ml})$ for $15 \mathrm{~min}$. at RT.

11. Wash in $2 \mathrm{mg} / \mathrm{ml}$ glycine in PBTw buffer for $5 \mathrm{~min}$.

12. Wash 3 times in PBTw buffer, 5 min. each.

\subsection{Pre-hybridization and hybridization}

13. Incubate worms in $500 \mu \mathrm{l}$ of 50\% PBTw/50\% hybridization buffer (HB) and incubate for $10 \mathrm{~min}$. at RT and 10 min. in $400 \mu$ undiluted $\mathrm{HB}$ at RT.

14. Pre-hybridize in pre-warmed $500 \mu \mathrm{HB}$ for $1 \mathrm{hr}$. at $48{ }^{\circ} \mathrm{C}$ and boil probe for $1 \mathrm{hr}$. at $99{ }^{\circ} \mathrm{C}$.

15. Dilute boiled probe in HB to give $100 \mu$ l of solution (1:1 dilution).

16. Boil diluted probe for $5 \mathrm{~min}$., cool to $48{ }^{\circ} \mathrm{C}$, remove pre-hybridization buffer and add the probe to the worms.

17. Hybridize for $24 \mathrm{hrs}$. at $48^{\circ} \mathrm{C}$.

\subsection{Washes and addition of antibody}

18. Remove the probe and wash once with $500 \mu \mathrm{l}$ hybridization buffer at $48{ }^{\circ} \mathrm{C}$ for $30 \mathrm{~min}$.

19. Wash in 3 parts HB: 2 parts PBTw buffer at $48{ }^{\circ} \mathrm{C}$, twice for $15 \mathrm{~min}$. each.

20. Wash in 1 part HB: 4 parts PBTw buffer at $48^{\circ} \mathrm{C}$, twice for $15 \mathrm{~min}$. each.

21. Wash with PBTw buffer at $48{ }^{\circ} \mathrm{C}$, twice for 10 min. each.

22. Wash with PBTw buffer at RT, for 10 min. each. 
23. Wash with PBT buffer (1X PBS; 0.1\% BSA; 0.1\% Triton X-100) at RT, twice for 20 min. each.

24. Dilute alkaline-phosphatase-conjugated anti-DIG antibody (1:1000).

25. Add $250 \mu \mathrm{l}$ to each tube and incubate overnight at $4{ }^{\circ} \mathrm{C}$.

\subsection{Developing reaction}

26. Wash 4 times with PBTw for 10 min. at RT.

27. Incubate worms for $10 \mathrm{~min}$. in staining solution.

28. Apply $50 \mu \mathrm{l}$ staining solution with BCIP/NBT (you may include $1 \mu \mathrm{g} / \mathrm{ml}$ DAPI if there is interest in visualizing nuclei).

29. Incubate worms $\mathrm{O} / \mathrm{N}$ at $4{ }^{\circ} \mathrm{C}$ under mild shaking.

30. Stop the reaction by washing the worms in $1 \mathrm{X}$ PBTw for $10 \mathrm{~min}$. at RT.

\section{Isolation of $\boldsymbol{P}$. pacificus genomic DNA for whole-genome sequencing}

Whole-genome sequencing (WGS) has become more affordable in recent years and is revolutionizing many areas in biology. Since nematodes have a small genome, this technique can be used at great effect to identify mutagen-induced changes linked to causal phenotypes (Zuryn et al., 2010). Thus, labor intensive protocols for mapping mutations can be avoided. A critical step to efficiently sequence genomic DNA of worms is to remove most bacteria, which is their source of food. Here we describe a method that takes advantage of the migratory behavior of dauers. We use a method to trap dauers in a buffer solution when they migrate away from the agar. The advantage of isolating genomic DNA from dauers over other stages is that this is a non-feeding stage. Therefore, there will be a minimal contamination from bacteria. With this method, more than $95 \%$ of the genome sequence is derived from the nematode.

\section{Protocol 7: Isolation of bacteria-free worm genomic DNA using the split plate method}

\section{Equipment and Reagents}

- $6 \mathrm{~cm}$ split plates (Compartmentalized Disposable Petri Dishes, 2 sections, Fisherbrand® 08-757-150).

- M9 Buffer.

- Epicentre Kit MasterPure ${ }^{\mathrm{TM}}$ Complete DNA Purification.

\subsection{Growing worms}

1. Prepare split plates with one half containing LB agar with E. coli OP50. Make sure that the height of the LB agar is just 3-5 $\mathrm{mm}$ below the top edge of the dividing wall. Fill the other half of the plate with M9.

2. Add 30 - 40 adult worms to the half of the plate with agar and OP50. To speed up the induction of dauers one can incubate worms at $25^{\circ} \mathrm{C}$ and also add pheromone extract (Protocol 8). Monitor the level of M9 in the half of the plate, so that dauers can migrate from the agar to the M9.

3. P. pacificus dauers float close to the surface of the M9 buffer. Use a transfer pipette to transfer them to a microcentrifuge tube. Other stages will also be found in the buffer, but they do not float close to the surface.

\subsection{Cleaning worms from microbial contamination}

4. Incubate worms in $50 \mu \mathrm{g} / \mathrm{ml}$ ampicillin and $50 \mu \mathrm{g} / \mathrm{ml}$ chloramphenicol on a rocker at medium speed for $48 \mathrm{hrs}$. If stages isolated are other than dauers or adults, do not incubate longer than $2 \mathrm{hrs}$. because the worms will die. 


\subsection{Genomic DNA isolation}

5. Follow instructions of the Epicentre kit.

\section{Extraction of organic compounds from worm supernatant cultures}

Nematodes secrete a large number of organic compounds. Although some of these compounds have been involved in signaling for dauer formation and mating, the function of most of them is not known (Robinette et al., 2011). Recently, some of these compounds have been implicated in the regulation of mouth dimorphism in $P$. pacificus (Bento et al., 2010). The extraction of organic compounds may be useful for characterization of additional ascarosides as well as for inducing a large proportion of dauers to extract genomic DNA (Protocol 7).

\section{Protocol 8: Isolation of organic compounds from worm supernatants.}

\section{Equipment and Reagents}

- Charcoal (Sigma-Aldrich 05112).

- Ethanol.

- 0.2 micron filter (e.g., IC millex LG from Millipore).

\subsection{Culture growth}

1. Prepare liquid culture containing dauers (1 liter; feed 3 times with $20 \%$ OP50, $50 \mathrm{ml}$ in total). Avoid having too many arrested young larvae in the culture.

\subsection{Preparation of active charcoal}

2. Boil charcoal with water in a beaker. Remove the supernatant.

3. Wash the charcoal several times until there are no floating particles.

4. Store the charcoal at $4{ }^{\circ} \mathrm{C}$.

\subsection{Extraction of organic compounds}

5. Pass the $500 \mathrm{ml}$ of the liquid culture twice through filter paper.

6. Centrifuge the supernatant at $12,000 \mathrm{rpm}$ with SLA-1500 rotor (Thermo Scientific $®$ ) for $30 \mathrm{~min}$.

7. Pass the supernatant through $0.2 \mu \mathrm{m}$ filter and transfer it to a beaker.

8. Add $25 \mathrm{ml}$ of active charcoal and stir with a magnetic stirrer for $1 \mathrm{hr}$.

9. Discard the supernatant.

10. Wash the charcoal 4 times with water in a beaker.

11. Remove as much water as possible with a pipette.

12. Transfer the charcoal to a conical flask with a glass plug (or Parafilm®).

13. Add $50 \mathrm{ml}$ ethanol and stir for $1 \mathrm{hr}$. Collect the eluate.

14. Add $50 \mathrm{ml}$ 1:1:1 (volume) mixture of acetone, toluene and ethanol. Stir for $1 \mathrm{hr}$. Collect the eluate.

15. Repeat previous step 5 times.

16. Evaporate combined eluate $(300 \mathrm{ml})$ with rotary evaporator. 
17. Resuspend the pellet with $2.5 \mathrm{ml}$ water (first add $500 \mu \mathrm{l}$ water to a single tube, dissolve the pellet and transfer to another tube).

18. Centrifuge at $14,000 \mathrm{rpm}$ for $20 \mathrm{~min}$.

19. Store the supernatant at $-20^{\circ} \mathrm{C}$.

\section{Morphological characterization}

Detailed descriptions of body morphology, gonad morphology and neuronal circuitry are valuable for comparative morphology and behavior between C. elegans and P. pacificus.

Protocol 9: Transmission Electron Microscopy of $\boldsymbol{P}$. pacificus (as performed by Daniel Bumbarger, Max Planck Institute for Developmental Biology, Tübingen, Germany)

\section{Equipment and Reagents}

- $100 \mathrm{~mm}$ deep metal specimen carrier.

- freezing apparatus (e.g., Bal-Tec HPM 010).

- liquid nitrogen.

- Whatman ${ }^{\mathrm{TM}}$ Nucleopore ${ }^{\mathrm{TM}}$ Track-Etched Membrane 110616, $12.0 \mu \mathrm{m}$ pore size, $25 \mathrm{~mm}$ circles.

- cryogenic tubes.

- freeze substitution unit (e.g., Leica EM AFS2).

- $5 \%$ gallic acid in acetone.

- acetone.

- $1 \%$ Osmium tetroxide (Crystalline, $100 \mathrm{mg}$ in glass ampoules, Electron Microscopy Sciences 19134). Store ampoules in air-tight container in reserved and labeled fridge. Store ready-to-use solutions at $-20^{\circ} \mathrm{C}$.

Caution: Osmium tetroxide is an extremely toxic, highly oxidizing substance. Fumes should by no means be inhaled nor get into the eyes. Always work under a chemical hood, wear disposable nitrile gloves, chemical goggles, lab coat and closed shoes. Waste and contaminated material have to be collected in a labeled leak proof waste container for pickup and proper disposal. For detailed safety instructions see for example: http://www.chemistry.ucla.edu/file-storage/publicview/pdfs/SOP_Osmium_Tetroxide.pdf.

- $0.1 \%$ Uranyl acetate in acetone with $2 \%$ water (Note: For $10 \mathrm{ml}$ Osmium/UA solution mix $9.75 \mathrm{ml} 100 \%$ acetone, $0.2 \mathrm{ml} \mathrm{H} 2 \mathrm{O}, 50 \mu \mathrm{l} 20 \%$ Uranyl acetate in methanol, $0.1 \mathrm{~g} \mathrm{OsO}_{4}$ ). You can use a 20\% Uranyl acetate in methanol stock solution, which can be kept at $-20^{\circ} \mathrm{C}$. The tiny amount of methanol does not matter.

- EPON (Epon-812 Kit, Electron Microscopy Sciences 13940).

- acetone/EPON series (3:1, 1:1,1:3).

- slide duplicating molds (Electron Microscopy Sciences 70170).

- ACLAR $^{\circledR}$ film (Electron Microscopy Sciences 50425).

- $2 \%$ Uranyl acetate.

- $1 \mathrm{~N} \mathrm{NaOH}$. 
- lead citrate.

- lead nitrate.

- lead acetate.

- sodium citrate.

\subsection{High Pressure Freezing}

1. Grow mature mixed plates with lots of young adult worms.

2. Wash worms off plate with water, pipette into Eppendorf tube, spin down, remove supernatant.

3. Place a $10 \mu \mathrm{m}$ deep metal specimen carrier on an ice-cold metal plate to relax worms prior to freezing.

4. Fill the metal carrier with a drop of worm suspension.

5. Cover with the flat side of a second carrier. Adjust the size of the drop so that the carrier is completely filled (no air left inside) but nothing will squeeze out when the top is put on.

6. High pressure freeze with a high pressure freezing apparatus.

7. Store frozen samples in liquid nitrogen.

\subsection{Freeze substitution}

8. Remove lid from metal specimen holder in liquid nitrogen. The bottom part contains the frozen worms.

In liquid nitrogen transfer the bottom part of the specimen holder with the frozen worms into some sort of small permeable chamber that fits into a $2 \mathrm{ml}$ cryogenic tube to prevent losing worms. Use custom-made 3-well metal chambers fitted with Nucleopore membranes (Figure 1). Alternatively, one can use cut pipette tips fitted with mesh.

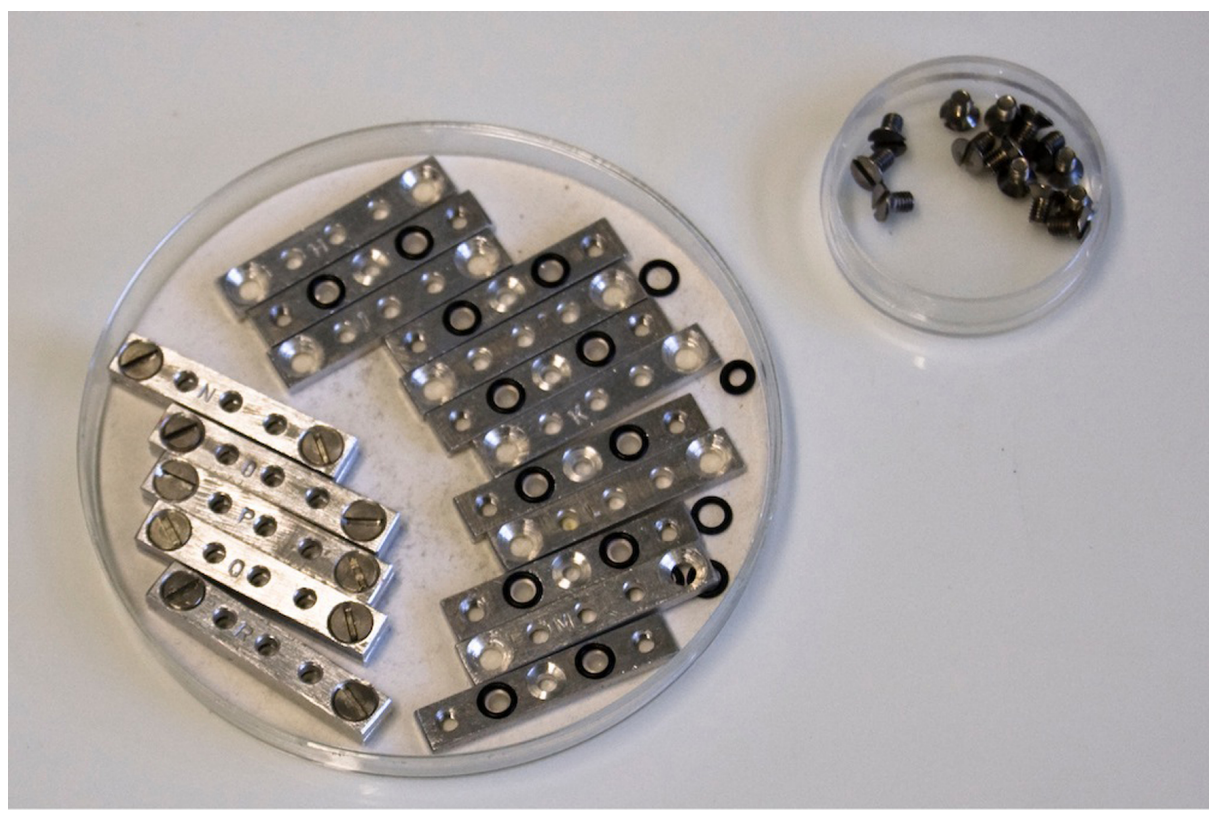

Figure 1. Custom-made 3-well chamber designed for freeze substitution. On the right are the bottom parts of the holders with 2 wells per holder fitted with an O-ring and on the left are the top parts to be screwed on after loading. 
9. Place $2 \mathrm{ml}$ cryogenic tubes filled with $5 \%$ gallic acid in acetone into an Automated Freeze Substitution machine (AFS) set to $-90^{\circ} \mathrm{C}$. The following freeze substitution steps are all carried out in the AFS. The machine can be programmed to hold or change temperatures over a wanted period of time.

10. Transfer the chambers with the worms into the cooled cryogenic tubes and incubate in $5 \%$ gallic acid in acetone for 48 hrs. at $-90{ }^{\circ} \mathrm{C}$.

11. Raise temperature by $4{ }^{\circ} \mathrm{C} / \mathrm{h}$ to $-60{ }^{\circ} \mathrm{C}(7.5 \mathrm{hrs}$.).

12. 5 rinses of $100 \%$ acetone at $-60{ }^{\circ} \mathrm{C}$.

13. Incubate in a solution of $1 \%$ Osmium tetroxide, $0.1 \%$ Uranyl acetate in acetone with water for $24 \mathrm{hrs}$. at $-60{ }^{\circ} \mathrm{C}$.

14. Raise temperature by $4{ }^{\circ} \mathrm{C} / \mathrm{hr}$. to $0{ }^{\circ} \mathrm{C}(15 \mathrm{hrs}$.).

15. 5 rinses of $100 \%$ acetone at $0{ }^{\circ} \mathrm{C}$.

16. Tubes can now be removed from the AFS.

\subsection{Infiltration}

17. Pass through a series of 3:1 acetone/EPON, 1:1 acetone/EPON 1:3 acetone/EPON and 3 changes in 100\% EPON at room temperature. Long times between changes improve infiltration, and the total time prior to polymerization is at least $48 \mathrm{hrs}$.

18. Embed in slide duplicating molds, with ACLAR film on the bottom of the mold.

19. Polymerize for $48 \mathrm{hrs}$. at $60^{\circ} \mathrm{C}$.

\subsection{Sectioning and staining}

For serial sections a thickness of $50 \mathrm{~nm}$ is advisable. The use of an auto-stainer saves a lot of time (e.g., QG-3000 EC TEM stainer, RMC products).

1. Post-stain with $2 \%$ Uranyl acetate for $10 \mathrm{~min}$. and modified Sato's lead stain for $20 \mathrm{~min}$. (see below).

2. Carbon coat the grids before inspection.

\subsection{Preparation of Modified Sato's lead stain (Hanaichi et al., 1986)}

Mix the following together and shake well in $50 \mathrm{ml}$ flask or bottle:

$0.20 \mathrm{~g}$ lead citrate (untreated, non-calcined lead citrate works fine)

$0.15 \mathrm{~g}$ lead nitrate

$0.15 \mathrm{~g}$ lead acetate

$1.00 \mathrm{~g}$ sodium citrate

$41.00 \mathrm{ml} \mathrm{CO}_{2}$-free distilled water (boiled and left to cool in tightly closed bottle)

Add $9.0 \mathrm{ml} 1 \mathrm{~N} \mathrm{NaOH}$, mix well, sonicate in water bath sonicator until solution becomes transparent. Store in sealed $50 \mathrm{ml}$ syringe at RT in the dark. This lead is stable for a long time. 
Protocol 10: Scanning Electron Microscopy of $\boldsymbol{P}$. pacificus (as performed by Jürgen Berger, EM facility, Max Planck Institute for Developmental Biology, Tübingen, Germany)

\section{Equipment and Reagents}

- Glutaraldehyde.

- $1 \%$ osmium tetroxide.

- PBS.

- Ethanol series $(30 \%, 50 \%$ and $70 \%)$.

- polylysine-coated $1 \mathrm{~cm}$ round coverslip.

- 24 well plates.

- $\operatorname{liquid} \mathrm{CO}_{2}$.

1. Grow nematodes on agar plates until bacteria are almost used up.

2. Wash worms off the plate with $1.5 \mathrm{ml}$ of water and transfer into Eppendorf tube.

3. Spin down gently at $2000 \mathrm{rpm}$ for $1-3 \mathrm{~min}$.

4. Wash 3 times with water to remove bacteria. The cleaner the worms the better.

5. Fix with $2.5 \%$ glutaraldehyde for $72 \mathrm{hrs}$. at $4{ }^{\circ} \mathrm{C}$.

6. Wash 5 times with PBS over a period of $24 \mathrm{hrs}$. at $4{ }^{\circ} \mathrm{C}$.

7. Post-fix with $1 \%$ osmium tetroxide in PBS for $5 \mathrm{hrs}$. on ice.

8. Wash 5 times with PBS over a period of $24 \mathrm{hrs}$.

9. Dehydrate in $30 \%, 50 \%$ and $70 \%$ ethanol, 24 hrs. each step. In $70 \%$ ethanol worms can be stored at $4{ }^{\circ} \mathrm{C}$ until further use.

10. Pipette a small volume of worms from the bottom of the Eppendorf tube onto a polylysine-coated $1 \mathrm{~cm}$ round coverslip. Worms will sink and adhere to the polylysine. Take care that worms do not dry out.

11. Transfer coverslip into a well of a 24 well plate that is filled with $70 \%$ ethanol.

12. Dehydrate in $95 \%$ and $100 \%$ ethanol, 24 hrs. each step.

13. Carry out critical-point-drying from $\mathrm{CO}_{2}$. $\left(5 \mathrm{hrs}\right.$. in liquid $\left.\mathrm{CO}_{2}\right)$.

14. Mount coverslips on stubs and sputter coat with $10 \mathrm{~nm} \mathrm{Au} / \mathrm{Pd}$.

\section{Protocol 11: Fluorescent staining of actin and DNA in dissected gonad arms}

\section{Equipment and reagents}

- Mouth pipette for all transfer steps.

- Slides with etched rings for decapitation (e.g., Gold Seal 3032).

- 27-gauge disposable hypodermic needles for decapitation.

- Deep depression slide, glass block dish or watch glass for fixation and staining. 
- PBS.

- Levamisole as anesthetic, stock solution.

- Para-formaldehyde, stock solution.

- Methanol, stored at $-20^{\circ} \mathrm{C}$.

- Acetone, stored at $-20{ }^{\circ} \mathrm{C}$.

- Ice bucket.

- Tween-20.

- BSA, stock solution.

- Egg buffer (118 mM NaCl, $48 \mathrm{mM} \mathrm{KCl,} 2 \mathrm{mM} \mathrm{CaCl}, 2 \mathrm{mM} \mathrm{MgCl}_{2}, 25 \mathrm{mM}$ Hepes, pH 7.3).

- AlexaFluor® 488 Phalloidin A-12379 (green), Molecular Probes, actin stain.

- or AlexaFluor® 546 Phalloidin A-22283 (red), Molecular Probes, actin stain.

- 4',6-diamidino-2-phenylindole (DAPI) D-1306, Molecular Probes.

- VectaShield mounting medium (H-1000, Vector Laboratories, Inc.).

- $5 \%$ agar in water for agar pads.

\section{Dissection:}

1. Pipette a drop of PBS with $0.25 \mathrm{mM}$ levamisole into etched ring on a microscope slide.

2. Transfer staged animals by mouth-pipette into the drop.

3. Decapitate animals with a 27-gauge disposable hypodermic needle at the base of the pharynx. Gonad arms will be squeezed out of the carcass. Carcasses may be removed or left in place.

\section{Fixation:}

4. Transfer gonad arms (with or without associated carcasses) into $2 \%$ para-formaldehyde (PFA) in PBS in deep depression slide or similar glass dish.

5. Fix for $1 \mathrm{hr}$., on ice.

6. Remove fixative, wash in PBS for 15 min., on ice.

Two alternative extraction methods are given below, methanol/acetone or Tween. Both work fine. Use one of the two.

\section{Extraction Method 1:}

7. Remove PBS, add methanol $\left(-20^{\circ} \mathrm{C}\right)$, extract for $5 \mathrm{~min}$.

8. Remove methanol, add acetone $\left(-20^{\circ} \mathrm{C}\right)$, extract for $5 \mathrm{~min}$.

9. Remove acetone, re-hydrated in PBS for $15 \mathrm{~min}$.

10. Remove PBS, add PBS containing the dyes of interest (see below). 


\section{Extraction Method 2:}

7. Remove PBS, add $0.1 \%$ Tween-20, $0.5 \%$ BSA egg buffer, extract for $10 \mathrm{~min}$.

8. Remove detergent, wash in fresh egg buffer solution.

9. Remove egg buffer, add egg buffer containing the dyes of interest (see below).

\section{Staining:}

11. Stain actin filaments with $0.15 \mu \mathrm{M}$ fluorescently labelled phalloidin in buffer of choice (1:50 dilution of AlexaFluor ${ }^{\circledR} 488$ or 546 Phalloidin)

12. Stain DNA with $1 \mu \mathrm{g} / \mathrm{ml}$ DAPI in buffer of choice. Phalloidin and DAPI staining can be done together or consecutively.

13. Stain for $30 \mathrm{~min}$. to $6 \mathrm{hrs}$.

14. Remove staining solution, wash in buffer of choice.

15. Store in Vectashield.

\section{Mounting:}

16. Mount gonads in Vectashield on agar pad.

17. Inspect in fluorescent microscope.

\section{Immunofluorescence of $P$. pacificus worms and embryos}

Protocols have to be modified for $P$. pacificus because the cuticle is thicker than in C. elegans.

1. The protocol from Finney-Ruvkun (http://www.wormatlas.org/antibodystaining.htm) (Finney and Ruvkun, 1990) is good for larvae and adults, but not for embryos. The method was first applied and optimized for $P$. pacificus by Kolotuev and Podbilewicz (Kolotuev and Podbilewicz, 2004). The detailed protocol can be found in the Pristionchus wiki

(http://www.pristionchus.org/wiki/index.php/Immunoflourescence_staining_of_whole_animals).

2. Good results were also obtained with "Freeze Crack in Tubes" in Ruvkun's Modified Witches Brew - followed by the standard protocol. The tube fixation method is described in Immunohistochemistry,

http://doi/10.1895/wormbook.1.105.1.

3. Curtis Loer's anti-Serotonin protocol with collagenase digestion also works in P. pacificus. A detailed description of the method is given at http://home.sandiego.edu/ cloer/loerlab/anti5htlong.html.

4. For a comprehensive survey of the available methods and reagents see Immunohistochemistry, http://doi/10.1895/wormbook.1.105.1.

\section{Transgenesis}

In contrast to $C$. elegans, injecting plasmids in the gonad of $P$. pacificus does not result in expression of extrachromosomal arrays, probably due to gene silencing. To overcome this problem, complex arrays have to be made (Schlager et al., 2009). Detailed protocols for making transgenics and description of transformation markers for P. pacificus are described elsewhere (Schlager et al., 2009; Cinkornpumin and Hong, 2011; Wang and Sommer, 2011). 


\section{Mapping mutants using molecular markers} websites:

Detailed descriptions of how to perform mapping of $P$. pacificus mutants can be found in the following

http://www.pristionchus.org/wiki/index.php/Mapping

http://www.pristionchus.org/wiki/index.php/Mapping_with_SSLP_markers

\section{Acknowledgements}

I am grateful to Ralf J. Sommer, Metta Riebesell, David Rudel, Daniel Bumbarger, Benjamin Schlager, Ray Hong, Jürgen Berger and Akira Ogawa for sharing and establishing many of the protocols described in this chapter. Work in APS lab is supported by NSF 1122095.

\section{References}

Ahringer, J. (2006). Reverse genetics. WormBook, ed. The C. elegans Research Community, WormBook, doi/10.1895/wormbook.1.47.1, http://www.wormbook.org. Article

Bento, G., Ogawa, A., and Sommer, R.J. (2010). Co-option of the hormone-signalling module dafachronic acid-DAF-12 in nematode evolution. Nature 466, 494-497. Abstract Article

Brenner, S. (1974). The genetics of Caenorhabditis elegans. Genetics 77, 71-94. Abstract

Chen, N., and Greenwald, I. (2004). The lateral signal for LIN-12/Notch in C. elegans vulval development comprises redundant secreted and transmembrane DSL proteins. Dev. Cell 6, 183-192. Abstract Article

Cinkornpumin, J.K., and Hong, R.L. (2011). RNAi mediated gene knockdown and transgenesis by microinjection in the necromenic nematode Pristionchus pacificus. J. Vis. Exp. 56, e3270. Abstract Article

Duerr, J. S. (2006). Immunohistochemistry. WormBook, ed. The C. elegans Research Community, WormBook, doi/10.1895/wormbook.1.105.1, http://www.wormbook.org. Article

Finney, M., and Ruvkun, G. (1990). The unc-86 gene product couples cell lineage and cell identity in C. elegans. Cell 63, 895-905. Abstract Article

Hanaichi, T., Sato, T., Iwamoto, T., Malavasi-Yamashiro, J., Hoshino, M., and Mizuno, N. (1986). A stable lead by modification of Sato's method. J. Electron Microsc. 35, 304-306. Abstract

Kolotuev, I., and Podbilewicz, B. (2004). Pristionchus pacificus vulva formation: polarized division, cell migration, cell fusion, and evolution of invagination. Dev. Biol. 266, 322-333. Abstract Article

Nolan, T.J., Aikens, L.M., and Schad, G.A. (1988). Cryopreservation of first-stage and infective third-stage larvae of Strongyloides stercoralis. J. Parasitol. 74, 387-391. Abstract Article

Pires-daSilva, A., and Sommer, R.J. (2004). Conservation of the global sex determination gene tra-1 in distantly related nematodes. Genes Dev. 18, 1198-1208. Abstract Article

Robinette, S.L., Ajredini, R., Rasheed, H., Zeinomar, A., Schroeder, F.C., Dossey, A.T., and Edison, A.S. (2011). Hierarchical alignment and full resolution pattern recognition of 2D NMR Spectra: application to nematode chemical ecology. Anal. Chem. 83, 1649-1657. Abstract Article

Sambrook, J., and Russell, D.W. (2001). Molecular cloning : a laboratory manual (Cold Spring Harbor, N.Y.: Cold Spring Harbor Laboratory Press).

Schlager, B., Wang, X., Braach, G. and Sommer, R.J. (2009). Molecular cloning of a dominant roller mutant and establishment of DNA-mediated transformation in the nematode Pristionchus pacificus. Genesis 47, $300-304$. Abstract Article 
Sommer, R.J. (2006). Pristionchus pacificus. WormBook, ed. The C. elegans Research Community, WormBook, doi/10.1895/wormbook.1.102.1, http://www.wormbook.org. Article

Stiernagle, T. (2006). WormBook, ed. The C. elegans Research Community, WormBook, doi/10.1895/wormbook.1.101.1, http://www.wormbook.org. Article

Sudhaus, W., and Fürst von Lieven, A. (2003). A phylogenetic classification and catalogue of the Diplogastridae (Secernentea, Nematoda). J. Nemat. Morphol. Syst. 6, 43-90.

Wang X., and Sommer, R.J. (2011). Antagonism of LIN-17/Frizzled and LIN-18/Ryk in nematode vulva induction reveals evolutionary alterations in core developmental pathways. PLoS Biol. 9, e1001110. Abstract Article

Yandell, M.D., Edgar, L.G., and Wood, W.B. (1994). Trimethylpsoralen induces small deletion mutations in Caenorhabditis elegans. Proc. Natl. Acad. Sci. U. S. A. 91, 1381-1385. Abstract Article

Zheng, M., Messerschmidt, D., Jungblut, B., and Sommer, R.J. (2005). Conservation and diversification of Wnt signaling function during the evolution of nematode vulva development. Nat. Genet. 37, 300-304. Abstract Article

Zuryn, S., Le Gras, S., Jamet, K., and Jarriault, S. (2010). A strategy for direct mapping and identification of mutations by whole-genome sequencing. Genetics 186, 427-430. Abstract Article

All WormBook content, except where otherwise noted, is licensed under a Creative SOMEREIGHISRESERVED Commons Attribution License. 